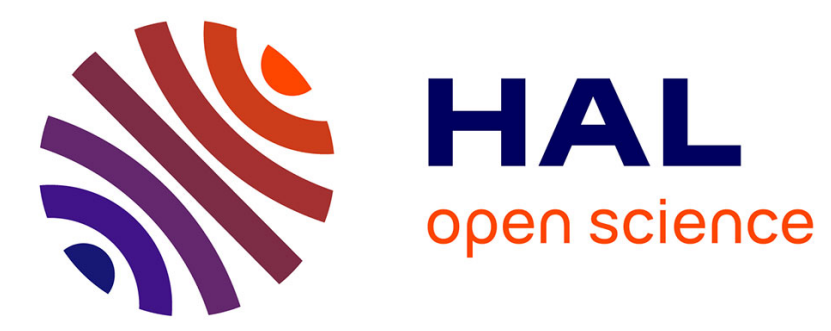

\title{
Kinematics of charged nanometric particles in silent discharges
}

\author{
N Jidenko, J.-P. Borra
}

\section{To cite this version:}

N Jidenko, J.-P. Borra. Kinematics of charged nanometric particles in silent discharges. Journal of Physics D: Applied Physics, 2005, 38 (4), pp.617-620. 10.1088/0022-3727/38/4/014 . hal03217040v2

\section{HAL Id: hal-03217040 \\ https://hal.science/hal-03217040v2}

Submitted on 18 Jun 2021

HAL is a multi-disciplinary open access archive for the deposit and dissemination of scientific research documents, whether they are published or not. The documents may come from teaching and research institutions in France or abroad, or from public or private research centers.
L'archive ouverte pluridisciplinaire HAL, est destinée au dépôt et à la diffusion de documents scientifiques de niveau recherche, publiés ou non, émanant des établissements d'enseignement et de recherche français ou étrangers, des laboratoires publics ou privés. 


\title{
Kinematics of charged nanometric particles in silent discharge
}

\author{
N. JIDENKO and J.P. BORRA
}

\author{
Laboratoire de Physique des Gaz et des Plasmas (CNRS -Univ. Paris XI) \\ Equipe Décharges Electriques et Environnement, Supelec, 91190 Gif sur Yvette, France
}
Journal of Physics D: Applied Physics, IOP Publishing, 2005, 38 (4), pp.617-620. $\langle 10.1088 / 0022-3727 / 38 / 4 / 014\rangle$. $\underline{\langle\text { hal }-03217040\rangle}$

\begin{abstract}
. $1 \mathrm{~mm}$ plane-to-plane configurations with or without dielectric barriers on the metallic electrodes are used to investigate AC electric precipitation of charged submicronic particles of controlled electrical mobility injected in a laminar flow. The collection efficiency is calculated from concentration measurement for different voltages. Below air ionisation threshold, experimental and theoretical collection efficiencies are consistent. Above air ionisation threshold, the current and collection efficiency increase with frequency and voltage related to the number of microdischarges per second and per surface unit. This study intends to check the influence of surface polarisation by microdischarges development on the collection of charged particles. Comparison between theory of collection in homogeneous AC field without microdischarge on the one hand, and measured collection efficiency with microdischarges on the other hand, proves that surface polarisation by microdischarges does not improve the collection efficiency, but enables either an increase of charge by ions repulsion from the surface, whatever the frequency is or a improved mixing at $60 \mathrm{kHz}$.
\end{abstract}

\section{Introduction}

Plane-to-plane dielectric barrier discharges (silent discharge SD) are well known and used for gas or surface treatments. In air at atmospheric pressure, discharges occur through fast $(\sim 20 \mathrm{~ns})$ thin filaments $(d \sim 100 \mu \mathrm{m})$ of cold plasma called microdischarges [1-3]. Microdischarges produce ions and reactive chemical species, so that DBD are useful tools for aerosol applications such as thin film deposition [4] nanotubes deposition [5] or filtration [6]. In these applications, both particle charging and transport are involved [7]. Ions can charge particles either by diffusion or field charging. Then charged particles can be collected in the reactor by the electric field.

However, microdischarges modify the collecting field. During the microdischarge propagation, the intensity of the electric field is high in front of the microdischarge head, but only so during nanoseconds. Then, when the microdischarge reaches the surface, electrical charges left on the surface make the electric field decrease, avoiding the development of other microdischarge in the area during the same half period (between voltage maxima). Then, after the field polarity inversion, this charge deposit increases the field up to the development of a microdischarge at the same place in the next half period. For a given geometry with sinusoidal voltage, the number of microdischarges per half period, distributed in time and space on the total surface of the plane-to-plane $\mathrm{DBD}$, depends on voltage amplitude and is nearly independent of voltage frequency [3]. At first approximation, microdischarges occur at the same locations; the evolution of the electric field profile is thus repeated at voltage frequency.

Experiments are conducted with positive nanometer sized particles of controlled mobility. The singly charged particles collection efficiency is then characterized according to voltage in DC or AC electric fields in metallic electroprecipitator (M ESP). Experimental collection efficiency, with or without microdischarges and theoretical one, calculated in homogeneous field (neglecting discharges and the surface polarisation influence), in dielectric barrier electroprecipitator (DB ESP) in AC are compared. In these conditions, the influence of: particle mobility, maximum field intensity and frequency on DC and AC ESP efficiencies are confirmed. Then, the influence of microdischarge on charged particle collection is established. 


\section{Experimental setup}

Metallic precipitator (M ESP): Two parallel planes of brass $(1 \times 3 \mathrm{~cm})$ are separated by $1 \mathrm{~mm}$. Dielectric Barrier ESP (DB ESP): Two parallel planes of alumina separated by $1 \mathrm{~mm}$ are polarized by $1 \times 3 \mathrm{~cm}$ brass electrodes thanks to a $1 \mathrm{kHz}$ or $60 \mathrm{kHz}$ sinusoidal power supply.

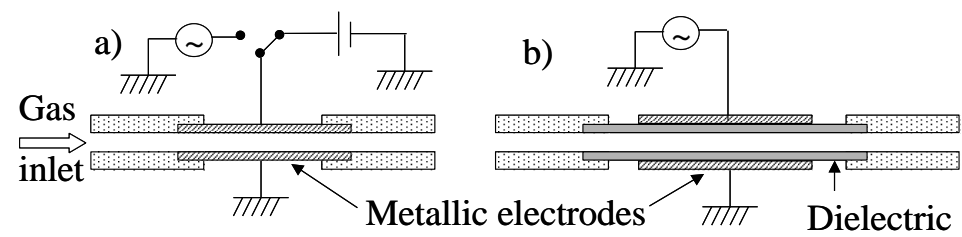

Figure 1: Schematic diagram of the experimental setup a) Metallic ESP b) Dielectric barrier ESP

A constant output atomizer $(0.05 \mathrm{~g} \mathrm{NaCl} / \mathrm{L})$ associated with a diffusion dryer produce unimodal $\mathrm{NaCl}$ aerosol centred on $40 \mathrm{~nm}$. A Differential Mobility Analyser selects a single mobility (5.4 $10^{-7}, 2.510^{-7}$ or $9.410^{-8} \mathrm{~m}^{2} \mathrm{~V}^{-1} \mathrm{~s}^{-1}$; mobilities of singly charged particles of $20 \mathrm{~nm} ; 30 \mathrm{~nm}$ and $50 \mathrm{~nm}$ ). The airflow velocity between the planes is fixed at $1.33 \mathrm{~m} \cdot \mathrm{s}^{-1}$ (22 ms residence time). The particle concentration is measured with a Condensation Particle Counter. The collection efficiency is defined as $100 *\left(C_{p o}-C_{p}\right) / \mathrm{C}_{\mathrm{po}}$ where $C_{p o}$ is the initial output concentration without applied voltage and $C_{p}$ is the output concentration, so that diffusion losses are not taken into account in the efficiency calculation.

\section{Experimental results}

The injected particles are below $50 \mathrm{~nm}$ to limit additional charging due to the ions of the discharge (less than $1 \%$ for $20 \mathrm{~nm}, 5 \%$ for $30 \mathrm{~nm}$ and $20 \%$ for $50 \mathrm{~nm}$ ). For a given voltage, theoretical and experimental efficiencies increase with particle mobility.

For the Metallic ESP, theoretical and experimental values are plotted versus the maximum electric field for DC polarisation on figure 1(a) and at $1 \mathrm{kHz}$ on figure 1(b).
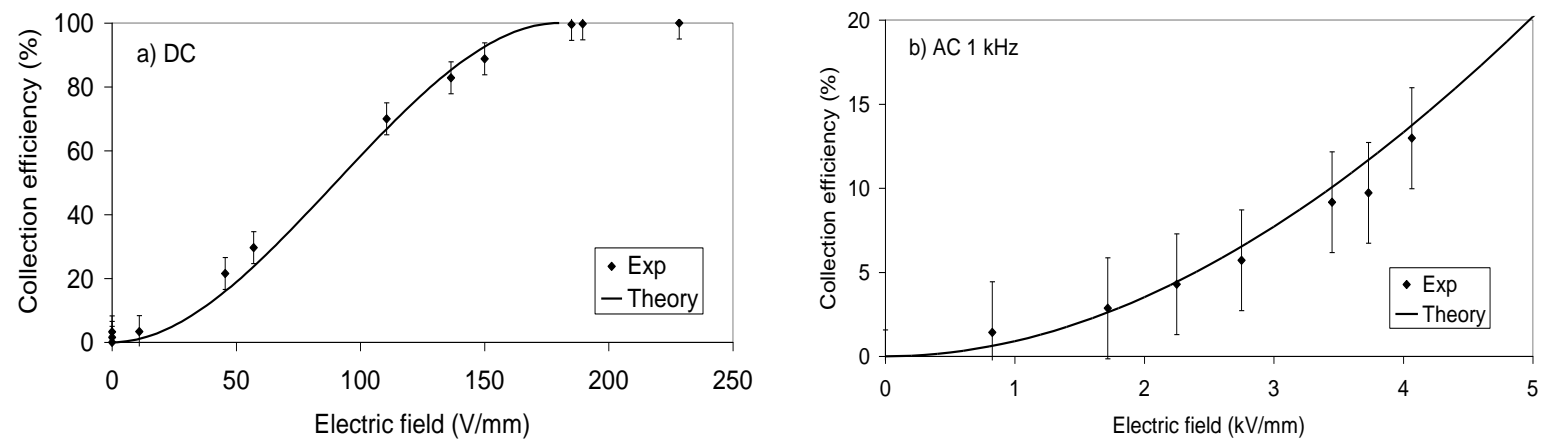

Figure 2: Collection efficiencies versus electric field in $\operatorname{M~ESP~}\left(\mu=2.510^{-7} \mathrm{~m}^{2} \mathrm{~V}^{-1} \mathrm{~s}^{-1}\right)$ a) DC b) AC $1 \mathrm{kHz}$

Whatever the DC or AC polarisation, the collection efficiency increases with electric field intensity.

The experimental Reynolds number $\left(R_{e}=\left(V_{g} \cdot d\right) / v=89\right)$ is far below the critical Reynolds number (2300). The flow regime is laminar and a collection theory of laminar flow is used with a parabolic gas flow velocity profile. Computation takes both electrical and entrainment forces into account. Gravity and thermophoresis are neglected.

Resolving the Newton's second law of motion, the amplitude of the particle movement is:

$$
\bar{z}_{p}=\frac{\mu_{p} E}{2 \Pi F}
$$


where $\mu_{\mathrm{p}}$ the particle mobility, $\mathrm{E}$ the amplitude of the electrical field and $\mathrm{F}$ the frequency. This amplitude defines the two volumes of collection of the particles above the dielectrics. Efficiency is obtained by integration of the particles flux in those volumes.

$$
\begin{array}{ll}
\eta=\frac{3}{d}\left(\bar{z}_{p}-\frac{d}{6}-\frac{4\left(\bar{z}_{p}-\frac{d}{2}\right)^{3}}{3 d^{2}}\right) & \text { if } \bar{z}_{p}<\mathrm{d} / 2 \\
\eta=1 & \text { if } \bar{z}_{p}>\mathrm{d} / 2
\end{array}
$$

Theoretical and experimental values are similar, confirming that collection only results from a competition between electrical and entrainment forces.

With AC, particles oscillate at voltage frequency. Their amplitude motion decreases with increasing frequency, so that collection is less efficient at $60 \mathrm{kHz}$ than at $1 \mathrm{kHz}$. Thus, collection efficiency at $60 \mathrm{kHz}$ is not presented because efficiency is under measurement accuracy. The slopes of the efficiencies versus electric field depend on velocity profile. The difference between AC and DC arises from the difference of volumes of collection. With DC, all the particles near the cathode are collected all along the reactor. Whereas with AC, all the particles near both electrodes are collected during the first period of the electric field on the first $1.3 \mathrm{~mm}$ at $1 \mathrm{kHz}$ and on the first $0.022 \mathrm{~mm}$ at $60 \mathrm{kHz}$ ).

For Dielectric Barrier ESP with AC polarisation, figure 3 shows the theoretical (full line) and the experimental collection efficiencies versus the homogeneous electric field in the gas. Figure $3 \mathrm{a}$ focuses on the collection at $1 \mathrm{kHz}$ for 20 and $30 \mathrm{~nm}$ singly charged particles (for corresponding mobilities of $5.410^{-7}$ and $2.510^{-7} \mathrm{~m}^{2} \mathrm{~V}^{-1} \mathrm{~s}^{-1}$ ) and figure $3 \mathrm{~b}$ at $60 \mathrm{kHz}$ for $30 \mathrm{~nm}$ singly charged particles. The homogeneous electric field in the gas is the amplitude of the electric field in the gap due to applied voltage (neglecting field perturbation associated to microdischarge development).
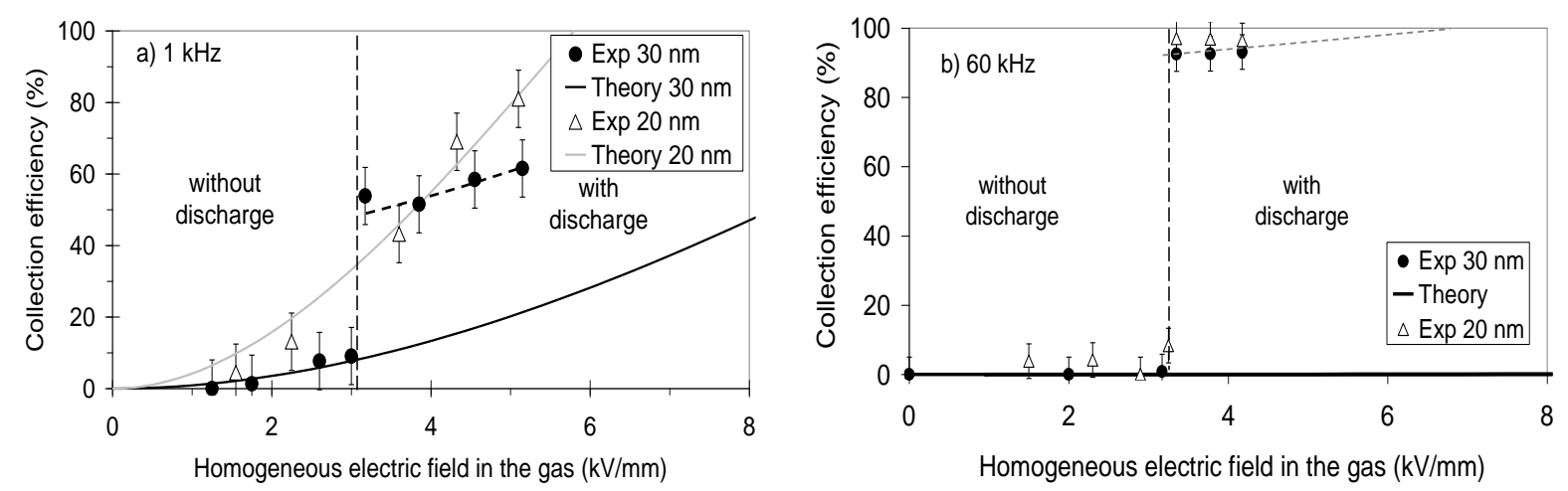

Figure 3: Collection efficiencies versus electric field in $\operatorname{BD~ESP~}\left(2.510^{-7} \mathrm{~m}^{2} \mathrm{~V}^{-1} \mathrm{~s}^{-1}\right)$ a) $1 \mathrm{kHz}$ and b) $60 \mathrm{kHz}$

Below the discharge threshold $(\sim 3 \mathrm{kV} / \mathrm{mm})$; measurements are consistent with theory, confirming that dielectric barriers are only polarized by applied voltage. Surface polarisation by the collection of charged particles is negligible.

Above the discharge threshold, collection efficiencies increase with the voltage related to the increase of the current and of the microdischarges number per second per surface unit.

At $1 \mathrm{kHz}$, (figure 2a), measurements are consistent with theory for the smaller particles of $20 \mathrm{~nm}$ with the lower probability of adding a charge on initially singly charged particle.

For bigger particles, measured efficiencies are 3 to 5 times better than the theoretical ones in homogeneous field (neglecting discharges and the surface polarisation influence). As similar results are obtained for these singly charged monodisperse particles of 30 and $50 \mathrm{~nm}$, only 
results for $30 \mathrm{~nm}$ are presented on Figure 3 for a mobility of $2.510^{-7} \mathrm{~m}^{2} \mathrm{~V}^{-1} \mathrm{~s}^{-1}(95 \%$ singly charged particle of $30 \mathrm{~nm}$ and $5 \%$ doubly charged particles of $43.3 \mathrm{~nm}$ ).

This tends to show that neglecting the local field modification by surface polarisation at the feet of filamentary microdischarges, that is to say that, assuming a perfect sinusoidal evolution of the homogeneous field can be done, when dealing with AC Electro-precipitation in DBD, if additional charging is excluded (e.g. for $20 \mathrm{~nm}$ singly charged particles, on Figure 3), while working below $1 \mathrm{kHz}$.

At $60 \mathrm{kHz}$ (figure 2b): (i) depending on input power, the surface temperature lies from $50^{\circ} \mathrm{C}$ to $150^{\circ} \mathrm{C}$. For a given input power, efficiency decreases from $93 \%$ at ambient temperature to about $80 \%$ at $90^{\circ} \mathrm{C}$, proving that thermophoresis is harmful to collection. So the SD is cooled down to maintain surface temperature below $50^{\circ} \mathrm{C}$ to limit thermophoresis, (ii) experimental efficiencies are better at $60 \mathrm{kHz}$ than at $1 \mathrm{kHz}$, whereas theoretical ones are worse and (iii) measured efficiencies are $10^{3}$ times better than theoretical ones.

Three processes can account for the improvement of collection efficiency by micro-discharges:

i) Ions left in the gap by the microdischarges could increase the number of particle charge. The charging efficiency depends on the product of ions density $\left(N_{i}\right)$ and the residence time $(\tau)$ of particle in this ion density. Ion mobility is around $10^{-4} \mathrm{~m}^{2} \mathrm{~V}^{-1} \mathrm{~s}^{-1}$, so that most of them are collected on the planes at both 1 and $60 \mathrm{kHz}$ in less than half a period. By assuming a collection of $99.9 \%$ of the ions, the mean product $\mathrm{N}_{\mathrm{i}} \tau$ lies below the critical $N_{i} \cdot \tau$ of $10^{7} \mathrm{~cm}^{-3}$.s, required to charge the particles, as confirmed by the injection of neutral aerosol leading to poor collection efficiencies of a few percents.

ii) Microdischarge induces local electric wind [9] and gas turbulences [10]. Turbulences modify the gas flux lines leading to mixing and concentration profile modification, so that particles initially outside the volume of collection can be collected.

iii) Particles can be trapped in electrostatic potential wells (sinks) due to charge deposits (induced by microdischarges) on surfaces. With the strong spatial heterogeneity and the fast temporal variations of the electric field due to microdischarges (cf. intro), particles can be slowed down, increasing the transit time and leading to electrostatic repulsion/attraction forces, so that particles initially outside of the volume of collection can be brought closer to the electrodes and collected.

To discuss the influence of mobility on collection efficiency with microdischarges, theoretical and experimental efficiencies are presented in table 1 at $4 \mathrm{kV}$ for 1 and $60 \mathrm{kHz}$.

\begin{tabular}{|c|c|c|c|c|c|c|}
\cline { 2 - 7 } \multicolumn{1}{c|}{} & \multicolumn{3}{c|}{$1 \mathrm{kHz}$} & \multicolumn{3}{c|}{$60 \mathrm{kHz}$} \\
\hline $\begin{array}{c}\text { Mobility } \\
\left(\mathrm{m}^{2} \cdot \mathrm{V}^{-1} \cdot \mathrm{s}^{-1}\right)\end{array}$ & $\begin{array}{c}\text { Theo } \\
(\%)\end{array}$ & $\begin{array}{c}\text { Exp } \\
(\%)\end{array}$ & $\begin{array}{c}\text { Theo } \\
/ \text { Exp }\end{array}$ & $\begin{array}{c}\text { Theo } \\
(\%)\end{array}$ & $\begin{array}{c}\text { Exp } \\
(\%)\end{array}$ & $\begin{array}{c}\text { Theo } \\
\text { /Exp }\end{array}$ \\
\hline $5.410^{-7}$ & 55 & 57 & 1 & 0.02 & 97 & $4.810^{3}$ \\
\hline $2.410^{-7}$ & 13 & 52 & 4 & 0.004 & 93 & $2.310^{4}$ \\
\hline $9.410^{-8}$ & 0.5 & 6.7 & 13 & 0.0006 & 87 & $1.410^{5}$ \\
\hline
\end{tabular}

Table 1: Theoretical and experimental collection efficiencies at $4 \mathrm{kV}$ for different mobilities

The factor between theoretical and experimental efficiencies increases with the diminution of particle mobility (table 1). In other words, the influence of microdischarges on collection is even more noticeable with particles of low mobility. That tends to support hypothesizes of turbulent mixing and of additional charging for particles bigger than $30 \mathrm{~nm}$. 


\section{Conclusions}

Before ionisation threshold for microdischarge development, whatever the DC or AC polarisation, (i) theoretical and experimental efficiencies increase with particles mobilities for any voltage, (ii) the collection efficiency increases with electric field intensity (iii) collection efficiencies decreases with increasing frequency and (iv) theoretical and experimental efficiencies are similar, confirming that collection only results from a competition between electrical and entrainment forces.

Above ionisation threshold for microdischarge development, the current and collection efficiencies increase with frequency and voltage related to the increase of the number of microdischarges per second and per surface unit.

Results tends to show that neglecting the local field modification by surface polarisation at the feet of filamentary microdischarges, that is to say that, assuming a perfect sinusoidal evolution of the homogeneous field can be done, when dealing with AC Electro-precipitation in DBD, if additional charging is excluded (e.g. for $20 \mathrm{~nm}$ singly charged particles), while working below $1 \mathrm{kHz}$.

However, microdischarges improve the collection efficiency even at $1 \mathrm{kHz}$ with bigger particles, probably because of the eventual additional charging. The influence of microdischarges on collection is even more noticeable with particles of low mobility at higher frequency, whatever the size is. Three processes can be involved in collection efficiencies improvement by microdischarges: (i) the number of charges per particle can be increased by the addition of discharge ions, (ii) turbulences can be induced by microdischarges and (iii) particles can be trapped in potential wells between the amounts of charges left by the microdischarges on the surfaces.

These observations confirm the competition between collection and extraction of particles in applications coupling filamentary discharges and aerosol. These results can be applied, for thin film deposition by collection of nanoparticles produced by plasma-gas interaction in volume and for nucleated nanoparticles production by plasma-surface interaction.

\section{REFERENCES}

[1] Kogelschatz U, Eliasson B and Egli W 1999 From ozone generators to flat television screens: history and future potential of dielectric-barrier discharges Pure Appl. Chem. Vol 71 No10 1819-1828

[2] Wagner H-E, Brandenburg R, Kozlov K V and Michel P 2001 J. Phys. D: Appl. Phys. 34 3164-3176

[3] Gibalov V. and Pietsch 2000 The development of dielectric barrier discharges in gas gaps and on surfaces J. Phys. D: Appl. Phys 33 2618-2636

[4] Massines F and Gouda G 1998 J. Phys D. Appl. Phys. 31 3411-3420

[5] Nozaki T., Okazaki K., Kortshagen U. and Heberlein J. GEC 2003 San Francisco

[6] Parker K.R. 1997 Applied electrostatic precipitation; Edition Parker

[7] Yoo K H et al. 1997 Charging and collection of submicron particles in two-stage parallel plate electrostatic precipitators Aerosol science and technology 27 308-323

[8] Goldman M and Goldman A., 1978 Corona discharges in Gaseous Electronics I, Ed Hirsh M N Vol 89b 119-166

[9] Blanchard D. and Atten P., 2001 Thèse de l'université Joseph Fourier, "Collecte des particules et caractérisation des couches de poussière dans un précipitateur électrostatique » [10] Han RJ, Gentry J.W (1994) Evolution of charge distribution of particles undergoing unipolar charging, Journal Aerosol science, Vol 25, N³, pp 499-508 